INOBIS: Jurnal Inovasi Bisnis dan Manajemen Indonesia

Volume 04, Nomor 01, Desember 2020

Nisa Ulin Nawa, Anas Hidayat

\title{
Peran Self-Brand Connection dalam Memediasi Kredibilitas Endorser terhadap Ekuitas Merek pada Marketplace Shopee
}

\author{
Nisa Ulin Nawa \\ Universitas Islam Indonesia \\ Anas Hidayat \\ Universitas Islam Indonesia \\ ulinnisa3@gmail.com \\ anas.hidayat@uii.ac.id
}

\begin{abstract}
Abstrak
Penelitian ini berjudul "Peran Self-Brand Connection dalam Memediasi Kredibilitas Endorser terhadap Ekuitas Merek". Penelitian ini bertujuan untuk menganalisis apakah self-brand connection dapat memperkuat pengaruh penggunaan selebriti yang kredibel terhadap ekuitas merek dari marketplace Shopee. Data pada penelitian ini adalah data primer dengan menggunakan kuesioner dan diisi oleh 250 responden. Teknik analisis yang digunakan dalam penelitian ini adalah analisis Structural Equation Modeling (SEM) dengan bantuan AMOS. Hasil penelitian menunjukkan bahwa kredibilitas endorser dapat berpengaruh terhadap ekuitas merek secara tidak langsung, yaitu dengan dimediasi oleh self-brand connection, namun kredibilitas endorser tidak terbukti dapat mempengaruhi ekuitas merek secara langsung.
\end{abstract}

Kata kunci: Self-brand connection, kredibilitas endorser, ekuitas merek

\section{Pendahuluan}

Dewasa ini, pertumbuhan ekonomi yang semakin meningkat berjalan seiringan dengan pesatnya perkembangan teknologi. Pemenuhan atas kebutuhan manusia yang beranekaragam, telah dipermudah dengan adanya kemajuan teknologi. Sebagai contoh, ketika seseorang merasa lapar namun sedang tidak bisa membuat makanan, sudah tersedia layanan pengantaran makanan hanya dengan melalui handphone. Bahkan ketika seseorang ingin berbelanja dapat dilakukan tanpa meninggalkan rumah, selama seseorang tersebut memiliki gawai yang terkoneksi dengan internet. Di Indonesia saat ini bisnis jual beli secara online sedang menjadi trend. Proses jual beli dapat dilakukan oleh pembeli dan penjual tanpa bertatap muka atau tanpa meninggalkan tempat dimana seseorang tersebut berada. Bisnis ini biasa disebut dengan e-commerce atau marketplace.

Toko jual beli online mulai popular di kalangan masyarakat Indonesia pada tahun 2006. Menurut hasil survey yang dilakukan oleh We Are Social, 96\% pengguna internet di Indonesia pernah menggunakan layanan belanja online (Pusparisa, 2019). Selain itu, data yang bersumber dari Statista mencatat pertumbuhan penggunaan toko online di Indonesia yang sangat pesat dilihat dari tahun 2017, tercatat pengguna e-commerce sebesar 139 juta pengguna yang kemudian tahun 2018 naik sebesar 10,8\% menjadi 154,1 juta pengguna (Jayani, 2019). Beberapa toko jual beli online yang sedang banyak dibicarakan di kalangan masyarakat Indonesia saat ini antara lain yaitu Shopee, Tokopedia, Buka Lapak, Lazada, dan lain sebagainya. 
INOBIS: Jurnal Inovasi Bisnis dan Manajemen Indonesia

Volume 04, Nomor 01, Desember 2020

Nisa Ulin Nawa, Anas Hidayat

Dalam rangka menarik hati konsumen, perusahaan-perusahaan jual beli online harus mengkomunikasikan alasan mengapa konsumen harus menggunakan jasa mereka dalam kegiatan jual beli online. Oleh karena itu, perusahaan harus melakukan promosi yang tepat agar pesan mereka dapat sampai kepada calon konsumen. Kegiatan-kegiatan dalam promosi antara lain yaitu iklan, penjualan pribadi, promosi penjualan dan hubungan masyarakat (Kotler \& Armstrong, 2008). Salah satu perusahaan toko jual beli online yang melakukan kegiatan promosi yaitu Shopee, dimana perusahaan ini melakukan periklanan sebagai media promosinya.

Menurut survey yang dilakukan oleh iPrice, Shopee merupakan perusahaan e-commerce dengan peringkat nomor satu pada toko aplikasi, baik Play Store maupun App Store dari awal tahun 2017 hingga kuartal ke-dua tahun 2019. Hal tersebut dapat diartikan bahwa Shopee banyak diminati oleh masyarakat. Shopee adalah sebuah marketplace yang berdiri sejak tahun 2015 yang beroperasi di negara-negara di kawasan Asia Tenggara seperti Singapura, Malaysia, Filipina, Indonesia, Thailand dan Vietnam. Kantor pusat Shopee berada di Singapura karena Shopee merupakan anak dari perusahaan SEA Group, sebuah perusahaan layanan digital yang berbasis di Singapura. Salah satu layanan yang diberikan oleh Shopee yaitu dapat menjamin keamanan transaksi antara penjual dan pembeli agar tidak terjadi hal-hal yang merugikan dengan cara sistem transaksi dipegang oleh Shopee. Pembeli dapat mencari dan memilih produk dari berbagai toko dengan berbagai pilihan harga, varian, hingga promo-promo yang ditawarkan oleh masing-masing toko.

Dalam menggiatkan promosi aplikasinya, Shopee melakukan kegiatan periklanan media promosi dalam bentuk iklan yaitu melalui media televisi (TV). Televisi mempunyai kemampuan yang kuat untuk mempengaruhi, bahkan membangun persepsi khalayak sasaran dan konsumen lebih percaya pada perusahaan yang mengiklankan produknya di televisi daripada yang tidak sama sekali (Mittal, 1994). Selain televisi, Shopee juga menggunakan platform lain sebagai media iklannya seperti di Youtube dan berbagai media sosial, karena masyarakat Indonesia saat ini hampir semuanya mengakses media-media tersebut setiap harinya.

Shopee menggunakan beberapa strategi marketingnya, salah satunya yaitu dengan menggunakan public figure sebagai endorser untuk menyampaikan produk dan layanannya kepada masyarakat. Endorser sering disebut sebagai direct source (sumber langsung), yaitu seorang pembicara yang mengantarkan sebuah pesan atau memperagakan sebuah produk atau jasa (Belch dan Belch, 2004).

Shopee menggandeng beberapa public figure sebagai endorser baik dari internasional maupun endorser lokal untuk masing-masing negara. Endorser internasional dari Shopee antara lain yaitu Blackpink (Korea) dan Cristiano Ronaldo (Portugis). Selain itu, Shopee juga menjadikan beberapa public figure lokal sebagai endorser di Indonesia seperti Prilly Latuconsina, Syahrini, dan beberapa selebriti lainnya. Selebriti dianggap sebagai perwujudan dari kepribadian dan makna yang berhubungan dengan gaya hidup (McCracken, 1989). Penelitian sebelumnya menunjukkan bahwa faktor penentu utama dari pengaruh endorser selebriti adalah kredibilitas yang dirasakan oleh konsumen dari seorang endorser tersebut (Amos dkk, 2008). Menurut Ohanian (Ishak, 2008) mengidentifikasikan 3 dimensi yang membentuk kredibilitas selebriti, yaitu Attractiveness (daya tarik), Trusthworthiness (tingkat kepercayaan), dan Expertise (keahlian).

Pada tahun 2019, Shopee bekerjasama dengan Cristiano Ronaldo sebagai brand ambassador yang sama artinya dengan endorser. Cristiano Ronaldo adalah seorang atlet sepak bola kelas dunia yang sangat terkenal. Atlet yang berasal dari Portugis ini merupakan idola bagi 
INOBIS: Jurnal Inovasi Bisnis dan Manajemen Indonesia

Volume 04, Nomor 01, Desember 2020

Nisa Ulin Nawa, Anas Hidayat

semua kalangan di seluruh dunia, tidak hanya dalam arena sepakbola saja, namun juga dikenal memiliki kepribadian yang baik. Selama ini, sebagian besar pengguna Shopee adalah wanita, yang mana kemudian Shopee lebih identik dianggap sebagai marketplace untuk wanita. Shopee berharap dengan adanya kerjasama tersebut, image Cristiano Ronaldo yang begitu kuat mampu memperluas target pasarnya agar tidak lagi mengenal gender.

Menurut (Spry, Pappu, \& Cornwell, 2011), kredibilitas endorser memiliki hubungan positif terhadap ekuitas merek berbasis konsumen. Kredibilitas endorser akan mempengaruhi ekuitas merek bila diiklankan secara terus-menerus (Tseng dan Lee, 2011), atau dengan kata lain ekuitas merek akan terdukung oleh seorang endorser selebriti yang kredibel pada benak konsumen (Biswas dkk, 2006).

Merek merupakan sesuatu yang memberi perbedaan antara produk satu dan produk yang lain dalam kombinasi, bentuk, sinyal, desain, atau nama (Kotler, 2008). Sedangkan ekuitas merek merupakan nilai yang diasosiasikan dengan merek oleh konsumen, tercermin dari dimensi kesadaran merek, asosiasi merek, persepsi kualitas dan loyalitas merek (Pappu dkk, 2006). Menurut Kotler dan Keller (2013), ekuitas merek (brand equity) berkaitan dengan seberapa banyak pelanggan merasa puas dan merasa rugi bila ada penggantian merek (brand switching), menghargai merek itu dan mengganggapnya sebagai teman, serta merasa terikat pada merek itu. Shopee berharap produk dan layanannya memiliki ekuitas merek yang baik sehingga pelanggan merasa puas dan terikat dengan Shopee, serta tidak memiliki keinginan untuk beralih pada $e$ commerce yang lain.

Menurut Dwivedi dkk. (2015), menyatakan bahwa kredibilitas endorser memiliki pengaruh positif terhadap self-brand connection. Sedangkan menurut Till (1998), endorser yang dianggap memiliki keterikatan terhadap kredibilitas (yaitu kepercayaan, daya tarik dan keahlian) membawa banyak keterikatan yang baik, kemudian konsumen akan mengidentifikasikan diri mereka, sama seperti selebriti yang terlibat di dalam suatu merek tersebut. Penelitian sebelumnya mengatakan bahwa selebriti endorser berperan dalam mempengaruhi self-brand connection (Dwivedi dkk, 2015). Oleh karena itu, Shopee berharap dengan menggunakan strategi iklan yang menggandeng beberapa public figure akan membuat konsumen memiliki keterikatan dan kesesuaian dengan produk dan layanan Shopee.

Dalam membangun merek, perlu diperhatikan keterikatan antara konsumen dengan merek yang dibangun. Hal ini disebut sebagai self-brand connections. Self-brand connection merupakan pembentukan hubungan yang kuat dan bermakna antara merek tertentu dengan identitas diri konsumen (Escalas, 2004). Selanjutnya menurut Chaplin dan John (2005), self-brand connection adalah pembentukan koneksi diri dengan merek yang sudah dikenal sebagai koneksi personal brand, yang terjadi ketika konsumen dan kepribadian pengguna memiliki hubungan yang erat dengan merek yang spesifik kemudian mereka memasukannya ke dalam identitas diri mereka. Ketika Self-brand connection menguat, konsumen dapat memperoleh manfaat seperti peningkatan harga diri, penerimaan sosial dan ekspresi individualitas (Escalas dan Bettman, 2003). Keller (dalam Dwivedi, Johnson, \& McDonald:2015) menyatakan bahwa pencapaian manfaat dari selfimage-relevant untuk memperkuat pengetahuan konsumen mengenai suatu merek, menjelaskan keterikatan dan sikap konsumen terhadap suatu merek yang akan terbenam di dalam ingatan konsumen, sehingga hal tersebut akan berdampak pada consumer-based brand equity. 
Berdasarkan dari latar belakang yang telah diuraikan di atas, maka penulis mengambil judul penelitian "Peran Self-Brand Connection dalam Memediasi Kredibilitas Endorser terhadap Ekuitas Merek Marketplace Shopee".

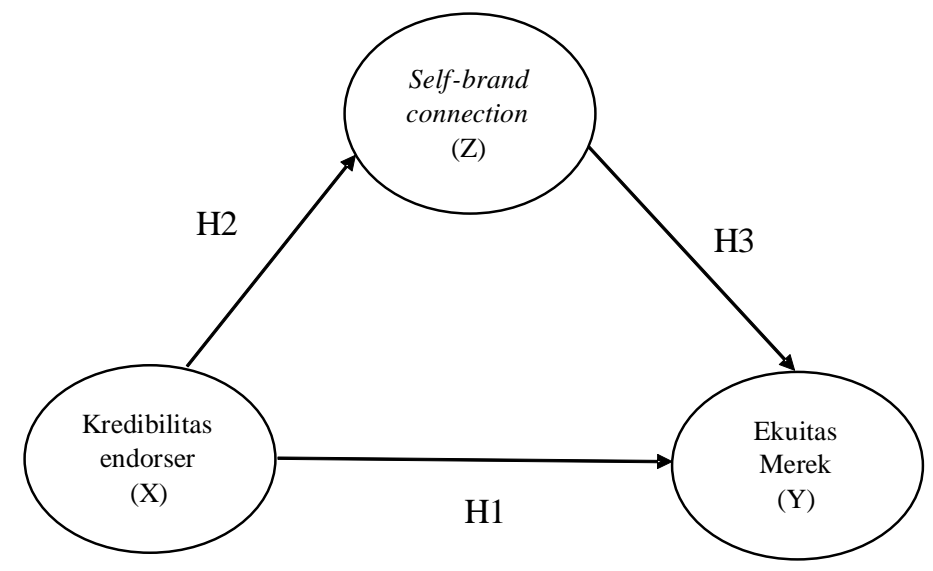

Gambar 1. Kerangka Pemikiran Teoritis

\section{Pengaruh Kredibilitas Endorser terhadap Ekuitas Merek}

Menurut Kotler dan Keller (2013), ekuitas merek berkaitan dengan seberapa tingkat kepuasan konsumen terhadap suatu merek, seberapa konsumen merasa rugi apabila berganti merek, seberapa konsumen menghargai merek dan menganggap sebagai teman, serta seberapa konsumen merasa terkait dengan merek tersebut. Sabdosih (2013) menyatakan bahwa salah satu tujuan dari perusahaan menggunakan selebritis atau public figure sebagai endorser dari produknya adalah untuk membentuk citra merek yang baik di benak konsumen, kemudian citra merek yang baik tersebut akan menjadi pertimbangan bagi konsumen dalam memilih produk di pasaran. Mengacu pada penelitian yang telah dilakukan oleh Dewantoro (2015) dengan judul "Analisis Pengaruh Endorser Credibility pada Brand Equity dan Minat Beli Konsumen" menyatakan bahwa kredibilitas model iklan berpengaruh secara positif terhadap ekuitas merek, maka dapat ditarik hipotesis:

H1: Kredibilitas endorser memiliki pengaruh positif terhadap ekuitas merek.

\section{Dasar Konseptual dan Hipotesis}

\section{Pengaruh Kredibilitas Endorser terhadap Self-brand Connection}

Selebriti meliputi simbol referensi asosiasi kelompok (Escalas, 2004), penelitian ini berharap bahwa selebriti endorser mempengaruhi self-brand connection. Dalam teori memori hubungan asosiasi (Keller, 1993), selebriti merepresentasikan sebuah tipe dari simpul informasi pada memori konsumen (Till, 1998). Ketika dengan adanya endorse yang membuat merek terhubung dengan selebriti, maka akan terbentuk hubungan antar simpul dalam memori konsumen. Hasilnya, atribut pada selebriti yang dirasakan akan berpindah pada merek yang didukung (McCracken, 1989). 
INOBIS: Jurnal Inovasi Bisnis dan Manajemen Indonesia

Volume 04, Nomor 01, Desember 2020

Nisa Ulin Nawa, Anas Hidayat

Berdasar dari apa yang telah peneliti uraikan diatas sejalan dengan penelitian yang dilakukan sebelumnya oleh Dwivedi, Johnson dan McDonald (2015) dengan judul "Celebrity Endorsement, Self-Brand Connection and Consumer-Based Brand Equity" bahwa kredibilitas endorser berpengaruh positif terhadap self-brand connections. Maka dari itu dapat disusun hipotesis sebagai berikut:

H2: Kredibilitas endorser memiliki pengaruh positif terhadap self-brand connection.

\section{Pengaruh Self-brand Connection terhadap Ekuitas Merek}

Menurut Moore dan Homer (2008), selebriti memiliki daya tarik yang dapat menciptakan citra diri yang diinginkan oleh konsumen. Proses endorsement akan membangun image ideal dari selebriti berkaitan dengan merek yang didukungnya yang kemudian konsumen dapat merasakan peningkatan harga diri, disebut sebagai self-brand connection. Ketika self-brand connection semakin kuat, konsumen akan memperoleh manfaat tambahan, seperti peningkatan harga diri, penerimaan sosial dan pengekspresian individu (Escalas \& Bettman, 2003). Oleh karena pencapaian dari manfaat yang telah diterima konsumen tersebut, pengetahuan konsumen terhadap merek yang telah didukung tersebut akan semakin menguat, tercermin pada asosiasi merek dan sikap dalam ingatan konsumen yang juga semakin menguat (Keller, 1993). Jika diambil kesimpulan, perkembangan dari self-brand connection menjelaskan bagaimana konsumen menjadikan selebriti sebagai gambaran makna sebuah merek. Maka dari itu dapat disusun hipotesis sebagai berikut:

H3: Self-brand connection memiliki pengaruh positif terhadap ekuitas merek.

\section{Metode Penelitian}

Metode penelitian yang digunakan dalam penelitian ini adalah metode kuantitatif. Menurut Sugiyono (2015), metode kuantitatif adalah sebuah metode penelitian yang didasarkan pada filsafat positivisme yang digunakan pada populasi atau sampel, serta menggunakan instrument penelitian statistik dalam pengumpulan data. Variabel penelitian dalam penelitian ini terdiri dari variabel independen yaitu Kredibilitas Endorser (X), variabel dependen yaitu Ekuitas Merek (Y) dan variabel intervening yaitu Self-brand Connection (Z).

Dalam penelitian ini, digunakan desain non probability sampling. Sampel yang digunakan adalah mahasiswa pengguna Shopee, baik yang pernah bertransaksi maupun yang belum serta tinggal di Daerah Istimewa Yogyakarta. Hair et al (2014) merekomendasikan jumlah sampel sebanyak 200 responden untuk memberikan dasar estimasi yang kuat, namun peneliti menambah 50 responden sehingga sampel yang akan digunakan dalam penelitian ini adalah sebanyak 250 responden.

Teknik yang akan digunakan untuk mengumpulkan data yaitu dengan menggunakan kuesioner. Kuesioner merupakan sebuah daftar pertanyaan tertulis yang diberikan kepada subjek yang diteliti untuk mengumpulkan informasi-informasi yang dibutuhkah oleh peneliti (Kusumah, 2011). Data yang dikumpulkan bersumber dari data hasil kuesioner pengguna aplikasi Shopee yang berlokasi di Yogyakarta. Responden dalam memberikan jawaban dalam kuesioner telah disediakan pilihan jawaban pada setiap pertanyaan. Jawaban kuesioner tersebut ada 5 pilihan 
INOBIS: Jurnal Inovasi Bisnis dan Manajemen Indonesia

Volume 04, Nomor 01, Desember 2020

Nisa Ulin Nawa, Anas Hidayat

karena kuesioner ini menggunakan skala Likert. Tujuan dari digunakannya skala Likert adalah untuk dapat mengukur sikap, pendapat, serta persepsi seseorang maupun kelompok terhadap fenomena sosial.

\section{Hasil Penelitian}

Karakteristik dari 250 responden yaitu terdiri dari 172 orang $(68,8 \%)$ perempuan dan 78 orang $(31,2 \%)$ laki-laki, berusia kurang dari 20 tahun sebanyak 8 orang $(3,2 \%), 20-25$ tahun sebanyak 210 orang $(84,0 \%)$ dan lebih dari 25 tahun sebanyak 32 orang $(12,8 \%)$. Sebanyak 70 orang $(28,0 \%)$ uang saku per bulan kurang dari Rp 500.000, 60 orang $(25,0 \%)$ antara Rp 500.000 hingga Rp 1.000.000 dan 120 orang (48,0\%) lebih dari 1.000.000. Responden yang paling banyak berasal dari UIN Sunan Kalijaga yaitu sebanyak 74 orang $(29,6 \%)$, UNY 45 orang (18,0\%), UGM 36 orang $(14,4 \%)$, UII sebanyak 27 orang $(10,8 \%)$, UPN sebanyak 7 orang $(2,8 \%)$, UMY sebanyak 3 orang $(1,2 \%)$, dan STIE YKPN sebanyak 3 orang $(1,2 \%)$. Sebanyak 55 orang $(22,0 \%)$ dikelompokkan dalam universitas lain-lain yang mana berasal dari UTY, AMIKOM, UNISA, UNSIQ, STAI Sunan Pandanaran, STIE IEU, PGRI, Poltekkes, ITNY, Sanata Dharma, UAD, STPN, UST dan UT.

Teknik analisis yang digunakan dalam penelitian ini adalah analisis Structural Equation Modeling (SEM) dengan dibantu software AMOS 22. Beberapa hal yang harus dilakukan dalam menganalisis model yaitu uji kecocokan model (goodness of fit), analisis model pengukuran dan struktural.

Hasil uji normalitas data setelah dilakukan eliminasi data outlier masih belum memenuhi syarat normalitas data karena nilai multivariate critical ratio sebesar 15,177 atau lebih besar dari 2,58. Menurut Ghozali (2016), jika asumsi normalitas tidak memenuhi, maka uji statistik tidak valid jika sampel penelitian kecil. Namun karena sampel pada penelitian ini lebih dari 200 atau dengan sampel besar, maka analisis dapat dianggap valid dan analisis dapat dilanjutkan.

Uji kesesuaian model digunakan untuk menggambarkan seberapa baik atau sesuai serangkaian pengamatan pada model. Pengujian kesesuaian model pada penelitian ini dilakukan dalam beberapa tahap, yaitu Chi Square $\left(X^{2}\right)$, GFI (Goodness-of-Fit Index), AGFI (Adjusted Goodness-of-Fit), NFI (Normalized Fit Index), CFI (Comparative Fit Index), IFI (Incremental Fit Index) dn RMSEA (Root Mean Square Error of Approximation). Uji kesesuaian model dilakukan dengan cara membandingkan kriteria kesesuaian dengan hasil perhitungan. 


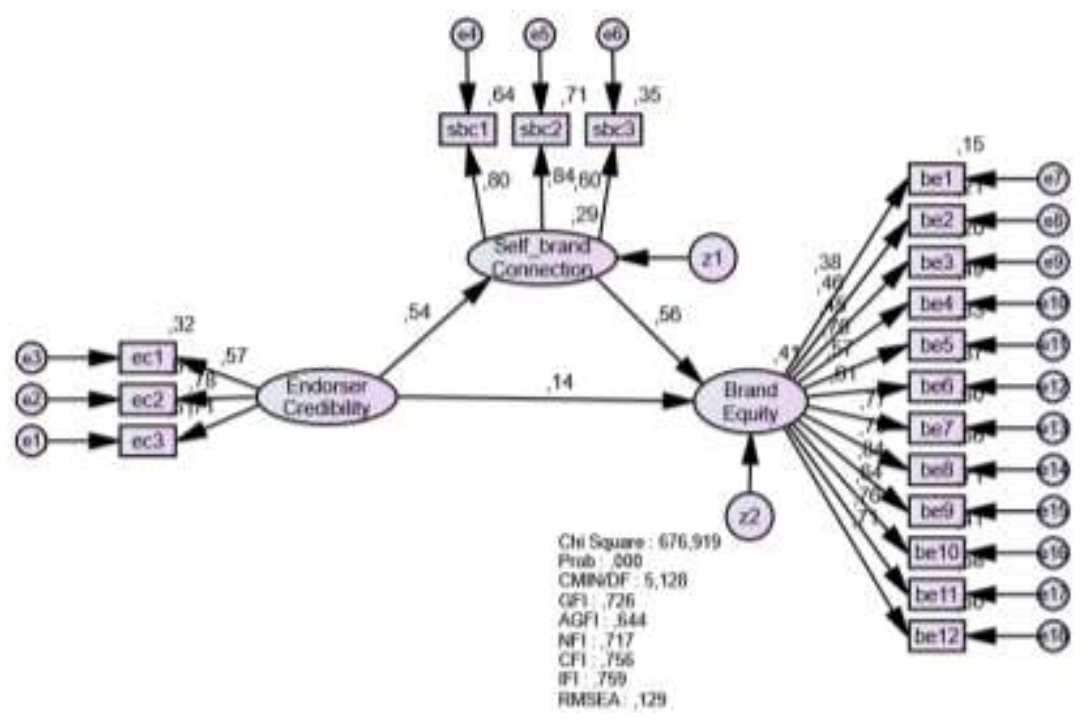

Gambar 2. Hasil Olah Data SEM

Gambar tersebut merupakan model persamaan struktural penelitian, dapat dilihat bahwa terdapat 3 indikator dengan nilai loading factor yang tidak memenuhi karena standar nilai loading factor yang disyaratkan adalah sebesar $>0,50$. Indikator yang tidak memenuhi tersebut yaitu be 1 , be 2 dan be 3 yang terdapat pada variabel ekuitas merek yaitu masing masing sebesar 0,38; 0,46 dan 0,45 sehingga ketiga item tersebut dihilangkan dalam analisis selanjutnya agar mendapatkan hasil yang lebih baik.

Tabel 1. Hasil Uji Kesesuaian Model

\begin{tabular}{|l|c|c|l|}
\hline $\begin{array}{c}\text { Goodness of Fit } \\
\text { Index }\end{array}$ & Hasil & Cut-off value & \multicolumn{1}{|c|}{ Kriteria } \\
\hline Chi Square & 103,585 & Diharapkan kecil & Memenuhi \\
\hline Probability & 0,013 & $\geq 0,05$ & Tidak memenuhi \\
\hline CMIN/DF & 1,400 & $\leq 2,00$ & Memenuhi \\
\hline GFI & 0,946 & $\geq 0,90$ & Memenuhi \\
\hline AGFI & 0,913 & $\geq 0,90$ & Memenuhi \\
\hline NFI & 0,947 & $\geq 0,90$ & Memenuhi \\
\hline CFI & 0,984 & $\geq 0,90$ & Memenuhi \\
\hline TLI & 0,977 & $\geq 0,90$ & Memenuhi \\
\hline RMSEA & 0,041 & $\leq 0,08$ & Memenuhi \\
\hline
\end{tabular}


Berdasarkan hasil perhitungan Goodness of Fit Index pada tabel, dapat dilihat bahwa sebagian besar indeks kesesuaian model telah memenuhi kriteria persyaratan yang diharapkan yaitu Chi square, CMIN/DF, GFI, AGFI, NFI, CFI, TLI dan RMSEA, sedangkan indeks yang tidak memenuhi yaitu Probability. Oleh karena itu dapat disimpulkan bahwa model penelitian ini telah memiliki ukuran kesesuaian model yang baik.

\section{Pembahasan}

Tabel 2. Hasil Estimasi Dengan Model AMOS

\begin{tabular}{|l|c|c|c|}
\hline \multicolumn{1}{|c|}{ Hipotesis } & $\begin{array}{c}\text { Koefisien } \\
\text { Standardized }\end{array}$ & $\begin{array}{c}\text { Nilai } \\
\text { Probabilitas }\end{array}$ & Hasil \\
\hline Kredibilitas endorser terhadap ekuitas merek & $-0,103$ & 0,365 & H1 ditolak \\
\hline Kredibilitas endorser terhadap self-brand connection & 0,551 & 0,000 & H2 diterima \\
\hline Self-brand connection terhadap ekuitas merek & 1,031 & 0,000 & H3 diterima \\
\hline
\end{tabular}

\section{Hasil Pengujian Hipotesis}

Penjelasan mengenai hasil pembuktian hipotesis adalah sebagai berikut:

a) Kredibilitas endorser tidak berpengaruh positif terhadap ekuitas merek, diketahui dari koefisien standardized sebesar $-0,103$ yang bernilai negatif, serta p-value sebesar 0,365 sedangkan $\alpha$ sebesar 0,05 . Hal ini menunjukkan bahwa H1 ditolak.

b) Kredibilitas endorser berpengaruh positif terhadap self-brand connection ini diketahui dari koefisien standardized sebesar 0,551 yang bernilai positif dan $p$-value $<\alpha$, yaitu p-value sebesar 0,000 sedangkan $\alpha$ sebesar 0,05 . Hal ini menunjukkan bahwa $\mathrm{H} 2$ diterima.

c) Self-brand connection berpengaruh positif terhadap ekuitas merek, diketahui dari koefisien standardized sebesar 1,031 yang bernilai positif dan $p$-value $<\alpha$, yaitu p-value sebesar 0,000 sedangkan $\alpha$ sebesar 0,05 . Hal ini menunjukkan bahwa H3 diterima.

\section{Kredibilitas Endorser Tidak Berpengaruh terhadap Ekuitas Merek}

Berdasarkan hasil pengujian yang telah dilakukan dengan analisis SEM diperoleh hasil bahwa tidak terdapat pengaruh kredibilitas endorser terhadap ekuitas merek. Hasil ini menunjukkan bahwa semakin tinggi atau semakin rendah nilai kredibilitas endorser tidak mempengaruhi nilai dari ekuitas merek. Hal ini berarti bahwa hipotesis pertama dalam penelitian ini ditolak.

Hal tersebut menunjukkan bahwa penggunaan selebriti sebagai endorser yang dilakukan oleh Shopee tidak dapat meningkatkan ekuitas merek. Ekuitas merek adalah nilai produk yang diasosiasikan oleh konsumen yang dapat menjadikan nilai tambah bagi produk tersebut. Ekuitas merek meliputi beberapa aspek seperti kesadaran merek, asosiasi merek, persepsi kualitas dan loyalitas merek, dan hasil penelitian mengatakan bahwa kredibilitas dari endorser marketplace Shopee tidak dapat meningkatkan aspek-aspek tersebut. 
INOBIS: Jurnal Inovasi Bisnis dan Manajemen Indonesia

Volume 04, Nomor 01, Desember 2020

Nisa Ulin Nawa, Anas Hidayat

Penelitian ini bertentangan dengan Ranjbarian, Shekarchizade, \& Momeni (2010) yang mengatakan bahwa kredibilitas endorser berpengaruh positif dan signifikan terhadap ekuitas merek. Namun Tseng dan Lee (2011) mengatakan bahwa kredibilitas endorser dapat mempengaruhi ekuitas merek apabila diiklankan secara terus-menerus, atau dengan kata lain kredibilitas masih dapat mempengaruhi ekuitas merek jika ditampilkan atau diiklankan berkalikali atau terus menerus.

\section{Kredibilitas Endorser Berpengaruh Positif terhadap Self-brand Connection}

Berdasarkan hasil pengujian yang telah dilakukan dengan analisis SEM diperoleh hasil bahwa terdapat pengaruh kredibilitas endorser terhadap self-brand connection. Berdasarkan hasil ini menunjukkan bahwa semakin tinggi nilai kredibilitas endorser maka self-brand connection juga akan meningkat. Hal ini berarti bahwa hipotesis kedua dalam penelitian ini diterima.

Penelitian ini sejalan dengan hasil penelitian Dwivedi, Johnson dan McDonald (2015) bahwa kredibilitas endorser berpengaruh positif terhadap self-brand connections. Maka dari itu langkah yang dilakukan oleh Shopee yaitu menggunakan endorser telah berhasil dalam meningkatkan keterikatan antara konsumen dengan produk layanan marketplace Shopee. Dalam hal ini Shopee menggandeng endorser yang kredibilitasnya dinilai baik oleh konsumen sehingga dapat meningkatkan nilai self-brand connection tersebut.

Hasil penelitian pada hipotesis kedua ini didukung dengan teori memori hubungan asosiasi yang dikatakan oleh Till (1998) bahwa selebriti dapat merepresentasikan sebuah tipe pada memori konsumen. Ketika dilakukan endorse atau dukungan pada suatu merek oleh selebritas tersebut maka akan terbentuk sebuah ikatan pada memori konsumen, kemudian atribut pada selebritas akan berpindah pada merek (McCracken, 1989) sehingga terbentuklah keterikatan atau hubungan antara konsumen dengan merek yang didukung oleh selebritas tersebut.

\section{Self-brand Connection Berpengaruh Positif Terhadap Ekuitas Merek}

Berdasarkan hasil pengujian yang telah dilakukan dengan analisis SEM diperoleh hasil bahwa terdapat pengaruh self-brand connection terhadap ekuitas merek. Berdasarkan hasil tersebut, menunjukkan bahwa semakin tinggi nilai self-brand connection maka dapat meningkatkan nilai ekuitas merek. Hal ini berarti bahwa hipotesis ketiga dalam penelitian ini diterima.

Penelitian ini sejalan dengan penelitian Dwivedi, Johnson dan McDonald (2015) yang menyatakan bahwa peran self-brand connection memiliki dampak positif terhadap ekuitas merek. Menurut Keller (2001), apabila tercapainya manfaat dari self-image-relevant yang dapat memperkuat pengetahuan konsumen mengenai suatu merek, maka akan memunculkan sebuah hubungan yang kemudian sikap konsumen terhadap suatu merek akan terbentuk dalam benak konsumen, sehingga akan mempengaruhi ekuitas merek.

Hal ini menunjukkan bahwa upaya yang dilakukan oleh marketplace Shopee dalam meningkatkan self-brand connection dapat berhasil meningkatkan ekuitas merek dari Shopee itu sendiri. Secara singkat, konsumen semakin merasa memiliki ikatan atau hubungan terhadap merek Shopee yang kemudian merek Shopee tersebut semakin melekat dalam benak konsumen. Nilai self-brand connection yang tinggi menunjukkan bahwa konsumen merasakan adanya peningkatan 
INOBIS: Jurnal Inovasi Bisnis dan Manajemen Indonesia

Volume 04, Nomor 01, Desember 2020

Nisa Ulin Nawa, Anas Hidayat

harganya diri, penerimaan sosial serta pengekspresian diri jika menggunakan suatu merek, dalam hal ini adalah marketplace Shopee. Hal tersebut menjadikan pengetahuan konsumen terhadap merek Shopee semakin menguat sehingga asosiasi antara merek dan sikap dalam ingatan konsumen juga menguat.

\section{Penutup}

\section{Kesimpulan}

Penelitian ini membuktikan bahwa kredibilitas endorser tidak berpengaruh secara signifikan terhadap ekuitas merek pada aplikasi marketplace Shopee. Hal ini menunjukkan bahwa upaya Shopee dalam menggunakan endorser tidak dapat meningkatkan ekuitas merek Shopee secara langsung. Endorser yang kredibel yaitu yang memiliki sifat dapat dipercaya, menarik dan ahli dalam bidangnya, sedangkan ekuitas merek berkaitan dengan kepuasan dan perasaan rugi apabila tidak menggunakan sebuah merek. Artinya, kredibilitas endorser pendukung Shopee belum dapat meningkatkan kepuasan konsumen terhadap Shopee.

Penelitian ini membuktikan bahwa kredibilitas endorser berpengaruh positif secara signifikan terhadap self-brand connection pada aplikasi marketplace Shopee. Konsumen menilai bahwa endorser Shopee memiliki kredibilitas yang baik, dapat dilihat dari endorser yang berhasil meningkatkan hubungan atau perasaan keterikatan antara konsumen dengan Shopee. Hal tersebut menunjukkan bahwa endorser dapat membuat konsumen mendapatkan manfaat seperti peningkatan harga diri, penerimaan sosial serta pengekspresian diri.

Penelitian ini membuktikan bahwa self-brand connection berpengaruh positif secara signifikan terhadap ekuitas merek pada aplikasi marketplace Shopee. Hal ini berarti bahwa semakin tinggi self-brand connection maka akan semakin tinggi pula ekuitas merek, atau dengan kata lain ketika keterikatan antara konsumen dengan Shopee semakin baik maka asosiasi merek akan menjadikan sikap ingatan dalam benak konsumen akan semakin kuat.

Berdasarkan beberapa kesimpulan tersebut dapat diambil benang merah dari hasil penelitian ini yaitu bahwa self-brand connection terbukti dapat memediasi pengaruh kredibilitas endorser terhadap ekuitas merek, dilihat dari kredibilitas endorser yang dapat mempengaruhi selfbrand connection dan self-brand connection dapat mempengaruhi ekuitas merek. Penelitian ini juga memberikan hasil bahwa kredibilitas tidak dapat mempengaruhi ekuitas merek secara langsung, melainkan harus dimediasi oleh self-brand connection.

\section{Saran}

Berdasarkan hasil penelitian ini maka peneliti menyarankan alangkah baiknya marketplace Shopee semakin memperkuat self-brand connection karena dapat meningkatkan ekuitas merek dari Shopee, baik dengan penggunaan endorser selebriti maupun dengan upaya lain. Hal lain yang perlu diperhatikan ke depannya adalah agar Shopee lebih cermat lagi dalam pemilihan endorser karena akan berdampak pada hubungan antara konsumen dengan Shopee. Jika hubungan antara konsumen dengan Shopee baik, ekuitas akan meningkat, maka semakin banyak konsumen yang akan menggunakan aplikasi Shopee untuk berbelanja secara online. 
Untuk peneliti yang nantinya akan melakukan penelitian terkait kredibilitas endorser, selfbrand connection dan ekuitas merek dari Shopee, disarankan untuk mencari variabel lain, baik variabel bebas, variabel terikat, variabel mediator maupun variabel moderator. Hal tersebut dimaksudkan agar penelitian semakin kompleks sehingga hasil penelitian dapat menambah serta mengembangkan ilmu pengetahuan.

\section{Daftar Pustaka}

Albert, N., Merunka, D., \& Valette-Florence, P. (2013). Brand passion: antecedents and consequences. Journal of Business Research, Vol. 66 No. 7, 904-909.

Amos, C. d. (2008). Exploring the relationship between celebrity endorser effects and advertising effectiveness A quantitative synthesis of effect. International Journal of Advertising. World Advertising Research Center.

Belch, G., \& Belch, M. (2004). Advertising and Promotion, An Integrated Marketing Communications Perspective, 6th Edition. New York: McGraw-Hill.

Belk, R. W. (1988). Possessions and the extended self. Journal of Consumer Research, Vol. 15 No. 2, 139-168.

Biswas, D., Biswas, A., \& Das, N. (2006). The Differential Effects of Celebrity and Expert Endorsements on Consumer Risk Perceptions. Journal of Advertising, Vol. 13, pp. 1-17.

Chaplin, G. E., \& John, D. R. (2005). The Development of Self-Brand Connections in Children and Adolescents. Journal of Consumer Research, 32(1):119-29.

Colwell, R. (2007). A Conceptual and Measurement for Brand Equity Research. Journal of Brand Measurement Strategy, Vol. 13, 1-17.

Dewantoro, R. R. (2015). Analisis Pengaruh Endorser Credibility pada Brand Equity dan Minat Beli Konsumen. Jurnal Ilmiah Universitas Bakrie, 806-817.

Durianto, D., \& Sugiarto. (2004). Brand Equity Tren Strategi Memimpin Pasar. Jakarta: PT Gramedia Pustaka Utama.

Dwivedi, A., Johnson, L., \& McDonald, R. (2015). Celebrity endorsement, self-brand connection and consumer-based brand equity. Journal of Product \& Brand Management, Volume 24 No. 5, 449-461.

Escalas, J. (2004). Narrative Processing: building consumer connections to brands. Journal of Consumer Psychology, 168-180.

Escalas, J. E., \& Bettman, J. R. (2003). You are what they eat: the influence of reference groups on consumers' connections to brands. Journal of Consumer Psychology, Vol. 13 No. 3, 339-348.

Ishak, A. (2008). Pengaruh Penggunaan Selebriti Dalam Iklan Terhadap Minat Beli Konsumen. Jurnal Siasat Bisnis Vol. 12 No. 2, 71-88.

Jayani, D. H. (2019, September 3). Databoks. Retrieved from Katadata: https://databoks.katadata.co.id/datapublish/2019/09/03/shopee-jadi-e-commerce-palingtop-dari-masa-ke-masa

Jewler, A. J., \& Drewniany, B. L. (2005). Creative Strategy in Advertising. USA: Wadsworth Thomson Learning.

Keller, K. L. (1993). Conceptualizing, measuring, and managing customer-based brand equity. Journal of Marketing, Vol. 57 No. 1, 1-22. 
Keller, K. L. (2005). Choosing the right brand elements and leveraging secondary associations will help marketers build brand equity. Marketing Management, Vol. 14 No. 5, 19-23.

Kotler, P., \& Armstrong, G. (2008). Prinsip-prinsip Pemasaran, Jilid 1. Jakarta: Erlangga.

Kotler, P., \& Keller, K. (2013). Manajemen Pemasaran, Jilid Kedua. Jakarta: Erlangga.

McCracken, G. (1989). Who is the celebrity endorser? Cultural foundations of the endorsement process. Journal of Consumer Research, Vol. 16 No. 3, 310-321.

Mittal, B. (1994). Public Assesment of TV Advertising: Faint Praise and Harsh Criticism. Journal of Advertising Research, pp: 100-117.

Moore, D. J., \& Homer, P. M. (2008). Self-brand connections: the role of attitude strength and autobiographical memory primes. Journal of Business Research, Vol. 61 No. 7, 707-714.

Ohanion, R. (1990). Construction and Validation of a Scale to Mesure Celebrity Endorser'Perceived Expertise, Trustworthiness, and Attractiveness. Journal of Advertising .

Ohanion, R. (1991). The Impact of Celebrity Spokespersons' Perceived Image on Consumers' Intention Purchase. Journal of Advertising Research, (February/March).

Pangestika, T. I. (2015). Pengaruh kredibilitas selebriti endorser pada ekuitas merek: pengujian kredibilitas merek sebagai variabel pemediasi. E-journal UAJY, 1-17.

Pappu, R., \& Cooksey, R. (2006). Consumer Based Brand Equity And Country of Origin Relationship: Some Empirical Study. Journal of International Business Studies, 38(5):726745.

Pornpitakpn, C. (2004). The Effect of Celebrity Endorsers' Perceived Credibility on Purchase Intention: The Case of Singaporeans. Journal of International Consumer Marketing, Vol. $16(2)$.

Pusparisa, Y. (2019, Desember 3). Databoks. Retrieved from Katadata: https://databoks.katadata.co.id/datapublish/2019/12/03/96-pengguna-internet-diindonesia-pernah-gunakan-e-commerce

Ranjbarian, B., Shekarchizade, Z., \& Momeni, Z. (2010). Celebrity Endorser Influence on Attitude Toward Advertisements and Brands. Europeam Journal of Social Sciences, Vol. 13 No. 3.

Royan, F. M. (2005). Marketing Celebrities. Jakarta: Elex Media Komputindo Kelompok Gramedia.

Sabdosih, Z. (2013). Pengaruh Variabel Celebrity Endorser terhadap Citra Merek L'oreal. Jurnal Ilmiah Mahasiswa FEB, 1-9.

Shimp, A. T. (2007). Periklanan Promosi (Aspek Tambahan Komunikasi Pemasaran Terpadu). Jilid I, edisi Terjemahan. Jakarta: Erlangga.

Sprott, D., Czellar, S., \& Spangenberg, E. (2009). The importance of a general measure of brand engagement on market behavior: development and validation of a scale. Journal of Marketing Research, 46(1):92-104.

Spry, A., Pappu, R., \& Cornwell, B. T. (2011). Celebrity endorsements, brand credibility and brand equity. European Journal of Marketing, Vol. 45 No. 6, 882-909.

Sugiyono. (2010). Statistika Untuk Penelitian. Bandung: Alfabeta.

Sugiyono. (2014). Metode Penelitian Pendidikan Pendekatan Kuantitatif, Kualitatif, dan R\&D. Bandung: Alfabeta.

Till, B., \& Shimp, T. (1998). Endorsers in Advertising: the case of negative celebrity information. Journal of Advertising, Vol. 27 No. 1, 67-81. 
INOBIS: Jurnal Inovasi Bisnis dan Manajemen Indonesia

Volume 04, Nomor 01, Desember 2020

Nisa Ulin Nawa, Anas Hidayat

Tseng, L., \& Lee, T. (2011). How Brand Image, Congruency between Celebrity Endorser and Brand, and Brand Attitude can Influece Tweens Purchase Intention through Peer Conformity. Fu Jen Catholic University Journal.

Widyajayanti, N. P., \& Kusuma, A. A. (2017). Peran self-brand connection dalam memediasi pengaruh kredibilitas endorser terhadap brand equity pada brand Guess. E-Journal Manajemen Unud, Vol. 6 No. 6, 3342-3369. 